Which Causes of an Experience are also Objects of the Experience? ${ }^{1}$

Tomasz Budek and Katalin Farkas (Central European University)

in Berit Brogaard (ed.) Does Perception Have Content? OUP 2014, pp. 351-370

\begin{abstract}
$\underline{\text { Abstract }}$
It is part of the phenomenology of perceptual experiences that objects seem to be presented to us. The first guide to objects is their perceptual presence. Further reflection shows that we take the objects of our perceptual experiences to be among the causes of our experiences. However, not all causes of the experience are also objects of the experience. This raises the question indicated in the title of this paper. We argue that taking phenomenal presence as the guide to the objects of perception, we can see that at least in two sensory modalities, smell and touch, there is no uniform answer to this question. The objects of olfactory and tactile experiences can move along the causal chain. Accordingly, the content of olfactory and tactile experience may vary.
\end{abstract}

\title{
$\underline{0 .}$ The content of perception
}

By 'perceptual experiences' we mean here experiences associated with the process of apparently gaining information through the five external senses: vision, hearing, touch, smell, taste. Perceptual experiences form a variety of sensory experiences in general; other varieties may include experiences that are not clearly associated with the process of external perception. In visual or auditory imagining, experiences are not produced by external senses. Bodily sensations, possibly some types of emotional experiences, or experiences of the passage of time may involve sensory modalities other than those associated with the five external senses.

Perception provides our primary access to the contingent features of the world around us, and at the first sight, this is what distinguishes perceptual experience from other sensory experiences. Through perception, we gain a conception of the world, and we acquire knowledge of its nature. The term 'content of experience' may be used in different senses (see Siegel 2013), but here we mean by the 'content' of an experience simply the way the experience presents the world. Philosophical interest in this feature is motivated by a number of considerations.

According to a strong current in the empiricist tradition, perceptual observation is the neutral arbiter among different theories of the world. To use Quine's

1 Earlier versions of this paper were presented at a workshop at Central European University, and at talks at the University of Bristol and the University of Cardiff. The authors are very grateful for audiences for their comments. Research for this paper has received funding from the European Commission's Seventh Framework Programme FP7/2007-2013 under grant agreement no. FP7238128, and from the project BETEGH09 supported by MAG Zrt. 
metaphor, theories face "the tribunal of experience". The metaphor suggests that we expect the tribunal to be impartial among the different theories. But is this expectation well founded? It has been suggested that the sharp distinction between raw and uninterpreted perceptual observation on the one hand, and subsequent theorising on the other, is untenable. According to this suggestion, the way we see the world, the way it appears to us, is already a result of joint work between theory and observation. This is one of the important questions about the content of experience: just what is it exactly that perceptual experience presents us?

This question has always interested philosophers: below we shall quote for example Aristotle's view on the objects of perceptual experience. However, it is worth mentioning some factors in and outside philosophy that have shaped the recent development of the issue. Starting already in the $19^{\text {th }}$ century, the empirical study of perception in cognitive psychology and later, in the $20^{\text {th }}$ century, in neuroscience, has became a huge enterprise, and we have now extensive experimental data and a whole array of theories about the psychological and physiological aspects of perception. We now know that the seemingly simple act of seeing an object is made possible by a complex operation of the perceptual system, using both hardwired and learned mechanisms. This gave a new impetus to asking the question of whether perception can be separated from the rest of our cognitive operations. This question, in turn, may have far-reaching consequences for our epistemological theories.

Among the senses, vision has always been in the primary focus of investigation both in philosophy and psychology. More recently, however, there has been a growing interest in the other senses, and it seems that focusing on vision may even have distorted our view of perception. As we mention below, some philosophers have even considered the view that for example the olfactory sense is not in the business of presenting the world at all: olfactory experiences have no content, they are mere sensations, mere modifications of one's consciousness. We defend a different view in this paper.

\section{Causes and objects of experiences}

We include under 'perceptual experiences' both veridical and non-veridical (illusory or hallucinatory) experiences. All successful perceptual experiences have an object. This is simply another way of saying that in a perceptual experience, something seems to be perceived - what seems to be perceived is the object. Among successful 
perceptual experiences we include illusions or misperceptions too, that is, perceptual experiences where some object is actually perceived, but it's perceived to be different from the way it is (so not all successful experiences are entirely veridical). But we don't include hallucinations: what distinguishes hallucinations is that the object one takes oneself to perceive is not actually perceived; it may not even exist. ${ }^{2}$

Our ordinary ways of speaking allow a wide variety of categories to be objects of perception: a property, a thing, an event, or in that-clause constructions, a fact. We see the colour of a dress, we taste a strawberry, we hear the train approaching, we feel with our fingers that the surface of the table is smooth. In case of a successful perceptual experience (when someone actually sees, hears, smells, tastes etc. something), the object of perception contributes to the cause of the perceptual experience. There are various views about the relata of the causal relation: they may be substances, events, facts, perhaps properties. We want to remain neutral on this issue, and would like to formulate our view so that it is compatible with either of these theories. For example, if someone believes that the relata of causation are events, then we say that when someone sees a glass, the glass is a constituent of some event that is the cause of the perceptual experience. From now on, we will say that the object is a cause of the experience without adding the qualification 'or constituent of an event or the fact which is a cause', but this will be understood implicitly.

An object of a perception is only one element in the causal chain leading to the experience. Someone wanted a drink, went to the kitchen to fetch a glass of water, the glass is now in front of her, light is reflected from its surface, some stimulus reaches the eye, changes are brought about in the retina, impulses are forwarded in the optic nerve, and so on. On various views of causation, all elements in this causal chain can be called the causes or 'some' causes of the perceptual experience. That is why it is better to say that the object of perception is 'a' cause, rather than 'the' cause of the experience.

It may seem that certain naïve realist theories of perception deny that the object of a perceptual experience is its cause, because they would say that the object is a constituent of the experience, and we don't normally regard constituents as causes. This is correct, but there is a way of modifying the claim which gives us everything we want, while taking naïve realist views on board. Naïve realists could agree that the

2 The boundary between successful misperceptions and hallucinations is probably blurred; it's not clear how serious a misperception can be so that we can still say that some object is actually perceived. But even if the distinction is vague, it is still a distinction, and an important one. 
object of perception is part of a causal chain that stands in a close relation to perceptual experience; however, on their theory, the final link in the causal chain would be not the perceptual experience itself, but rather a brain state that partly constitutes the experience. Thus, naïve realists would agree that if no element in the causal chain leading to the brain-state is the object of the experience, then the experience is a hallucination (this is a sufficient, but perhaps not a necessary condition for hallucinating). The object of perception is an element in the causal chain leading to the experience, or to a brain-state that is a constituent of the experience. In what follows, we will mean this disjunct when we refer to the causal role of the object.

It is necessary for a successful perceptual experience that its object is found among the causes of the experience. However, it should be obvious that not all causes of the experience are also its objects; returning to the above example of seeing a glass, what one certainly sees in the situation is the glass, but this cannot be said of the links in the causal chain before and after: say, the hand placing the glass on the table, or the surface of one's retina. Even if the subject of experience knows that these things participate in the causal chain, and hence she can infer to their presence or existence from the fact that she has the perceptual experience, it would still not sound right to say that these are the objects of her experience.

\section{A question}

In the previous section, we established that an object of an experience must be a cause of the experience, but not all causes are objects. Can we say something in general about which elements in the causal chain - leading to a successful perceptual experience - are the objects of the experience? What is it about the glass, and about the surface of the retina, that makes it so compelling that the first is the object of perception, and the second isn't? We do not assume that there must be a general answer to this question - maybe there are different cases, or maybe this is just a primitive fact; but the question is worth asking.

This issue hasn't received much attention in this general form (and won't be resolved entirely in this essay). Some particular cases and some issues in the close vicinity have been discussed in some detail, for example in the debate about the immediate objects of perception; on this, we will say more in the next section. There is a debate for example on the objects of olfaction: do we perceive odours, or sources of odours? In the tactile modality, do we perceive the skin or the object touching the 
skin?

In this paper, we would like to argue that the question concerning the objects of a given perceptual modality cannot always be given a uniform answer. For example, in the olfactory modality, one can't say that we always smell an odour, or that we always smell the source of odour. We claim that on some occasions we smell one, on some occasions the other or both. Perception can take different kinds of things as objects, in a sense we shall explain below: different elements in the causal chain leading to the experience can become the objects of perception. We shall investigate this claim in more detail in the case of olfactory and tactile experiences, but we believe that similar considerations may apply to all sensory modalities.

If we can answer the question of what the object of experience is, we gain knowledge also of the content of the experience. The content is plausibly regarded as representing the objects as being in a certain way. If the objects of perception vary, then contents also vary.

\section{Related questions}

Since the possible objects of perceptual verbs show a great variety in a number of dimensions, philosophers sometimes raise the question of whether some objects are special in a certain sense. First, the investigation has to be narrowed - if possible - to what we literally regard as cases of perceiving something. We are not interested in all cases when it is simply natural to say that we perceive something. For example, it is natural to say that we can see that it's cold outside when we see people hurrying on the street huddled in their coats. However, many would disagree with the claim that we can literally see temperatures, and would say instead that we learn about the temperature in this case by seeing the shapes and colours of people moving. One could ask for a general theory of all cases where perceptual verbs take objects in natural everyday constructions. This is an interesting question, but not the one in the focus of this paper. We are looking for those objects which are literally perceived (assuming, of course, that this distinction can be made.)

An issue related to our discussion is the question of which properties can be represented ${ }^{3}$ in experiences in a sensory modality. This issue can be regarded as the

3 Which properties can be represented - or presented, if someone doesn't want to commit herself to the idea that perceptual experiences are representational. Hopefully, taking sides on this issue is orthogonal to the question we are asking. Hence we shall often talk of representation and content, but what we say should be relevant for those who believe that perceptual experience is not 
complement of our question concerning which things are the objects of an experience. Assuming that the content is the representation of things as having certain properties, one issue is what kind of properties, another issue is what kind of things can enter the content of a perceptual experience.

Recently there has been a lively debate of the question of which properties are represented in experience. The debate is largely concerned with visual experiences, where on one side of the debate we find claims that visual experiences represent only a limited range of properties: colours, shapes, motion, perhaps a few more, while on the other there are views according to which visual experiences can represent properties like that of being a tree or of being a house. ${ }^{4}$ Susanna Siegel, who defends the second, more liberal view, discusses for instance the case of someone who gradually develops a recognitional capacity for pine trees (Siegel 2006, e.g. pp. 491500). Siegel thinks that while previous to this development, the subject may have represented only the shape and colour of pine trees in her experiences, once something's being a pine tree becomes visually salient to her, this feature becomes part of the content of her visual experiences. There are some notable differences between the case of representing properties and representing things, but these differences aside, we believe that in some circumstances, a similar phenomenon occurs in connection to the things that are the objects of our experiences. And as we shall see below, there are important parallels between the issues of which properties and which things enter the content of a perceptual experience.

A further question about the objects of perception concerns the proper objects of a sense, that is, the objects that can be perceived by that sense only ${ }^{5}$ for example, smells can arguably be perceived only by the olfactory sense. Yet another question is about the primary objects of perception: these are objects that are always perceived whenever something is perceived in a sensory modality. For example, people have argued that whenever we hear something, we always hear a sound - indeed, if we hear anything, we hear it by or in virtue of hearing a sound. As David Sanford (1976) makes it clear, though sounds are also proper objects of hearing, being proper and

representational (e.g. Travis 2004).

4 An example of the former, called sometimes 'sparse' or 'conservative' view, is Tye (1995, pp. 140141). Some of the recent defenses of the 'rich' or 'liberal' view include Siegel (2006) and Bayne (2009).

5 See Sanford (1976), p. 190. The question goes back to Aristotle's theory of 'proper sensibles'. It is sometimes thought to have significance for the issue of distinguishing different sensory modalities from each other; see Nudds (2004). 
being primary are different conditions; something could be specific to a sense yet not involved in every experience through that sense, and something could be involved in every such experience without being specific to that sense.

Proper and primary 'objects' are sometimes conceived as qualities: for example, when it is claimed that colours are proper objects of vision. In this case, 'object' is not an ontological category, but simply signals that something is perceived in a certain modality. But proper and primary objects need not always be qualities. A 'sound' can be understood as a spatio-temporally located physical existent. ${ }^{6}$ Similarly, smells or tastes (or perhaps 'odours' and 'flavours') can be understood not as qualities, but as quantities of certain chemicals. If we wanted to find an equivalent of sounds, odours and flavours in the visual modality, it would be something like a coloured expanse, rather than simply a colour.

Developing a theory of the proper and primary objects of perception - if it can be done - goes some way towards answering our question, but doesn't go the whole way. For one thing, saying that a coloured expanse is the proper and primary object of sight doesn't answer the question of why it is the glass we see, but not the retina or the glassmaker, given that all three have coloured surfaces. Further, we are interested in all objects of perception, including improper and secondary ones, and anyone who allows for such objects will still have to single out some elements in the causal chain. Finally, our question stands even if there are no proper and primary objects of perception. So the debate about the proper, primary or direct objects of perception, though relevant to our purposes, is not exactly what we are interested in.

\section{Objects of olfactory experiences}

Our question was: which elements in the causal chain leading to (the final constituent of) perceptual experiences are the objects of experience? That is, where, along the causal chain, do we locate the experience-independent thing that we perceive? We do not have a general explanatory answer to this question, but we have a claim that puts a constraint on possible explanation: that within at least some sensory modalities, different kinds of things can be the objects of a perceptual experience. ${ }^{7}$ Let us

6 This question is discussed for example in O'Callaghan (2007).

7 The phenomenon is general: given that some bodily sensations arguably have an object, the same observation applies to bodily sensations too. In this paper, we focus mainly on perceptual experiences, but we discuss for example tactile sensations (i.e. awareness of bodily parts in the tactile mode), since they have a very intimate connection with external tactile perception. 
illustrate this first on the example of olfactory experiences.

On some views, olfactory experiences have no object. Christopher Peacocke, for instance, allows for the possibility that "a sensation of smell (...) may have no representational content of any sort, though of course the sensation will be of a distinctive kind" $(1983$, p. 5). As 'content' is used in this paper, if the sensation has no content, it has a fortiori no object either.

William Lycan in "Layered Perceptual Representation" considers a different view:

(...) there are objects other than roses that set off the rose smell artificial rose smells can be made of any substance whose molecules are shaped similarly to those of roses. The point is not that the nose can be fooled. Au contraire; it is that in the artificial case, the nose is not fooled, and the rose smell is not incorrectly tokened. An artificial rose that produces the rose smell is smelled correctly, for it does have that smell even though it is not a rose. (Lycan 1996, p. 90)

Someone who accepted this line would agree that we often classify particular smells with respect to the objects likely to give out those smells - in this case with reference to roses. However, she would think that we correctly say that we smell 'rose smell' whenever rose odour is present; hence our experiences are correct or incorrect not with respect to roses, but rather with respect to rose odour. Therefore odours are better candidates for being the objects of olfactory experiences.

At the end, however, Lycan turns against the view that the objects of olfactory experiences are only odours. Lycan is persuaded here by Ruth Millikan's teleosemantics-based arguments. On the teleosemantics story, perception indicates for the organism the presence of those things which are useful for its survival, and in the case of olfaction, these things are presumably not odours, but the source of odours. Hence:

(...) if smells do represent anything, they do after all represent environmental objects of potential adaptive significance. Surely that is what olfaction is for, to signal food, predators, shelter, mates, and other objects of interest ultimately derivative from those ... (Lycan 1996, p. 92) 
However, Lycan is reluctant to give up the view that olfactory experiences represent odours, so he settles for a 'multi-object' view: olfactory experiences represent both roses and odours, indeed they represent the former 'by' representing the latter.

The difference between smelling the odour of coffee and smelling a thing like coffee in the cup illustrates the sense in which olfactory experiences can have different type of objects: different elements are singled out in the causal chain leading to the experience. This means that there are different conditions for the experience being successful. If the object of smell is coffee, and there is no coffee in the room, then any apparent experience of coffee is hallucinatory. But if the object is an odour which happens to be emitted by coffee, then an experience can be veridical even if there is no coffee around, but only the smell lingers. ${ }^{8}$

At first sight, this relation between perceptual error and the content of experience may suggest a way of finding out what the proper objects of perception are: those whose presence and properties are responsible specifically for perceptual, rather than other kinds of error. Unfortunately, this observation, while valid, doesn't advance the debate at this stage, because we don't really have direct intuitions about perceptual error independently of what we take to be the objects of perception. All parties agree that in the case of mistakenly thinking that one is smelling a real rose rather than an artificial one, there is an error. But the question of whether the mistake is perceptual or cognitive, is the same as the question of what the object of perception is.

\section{The phenomenal presence of objects}

We are interested in the question of which causes of a perceptual experience are also objects of the experience. In this paper, we argue that at least within some sensory modalities, there is no uniform answer to this question. We have illustrated this claim so far on olfactory experiences: the object can be an odour, or the source of an odour. Or in any case, these are candidates for being the object of the appropriate experiences. But perhaps there is a way of deciding the issue?

8 In fact, the view that smells have no objects at all can be regarded as a 'limiting case' of moving up in the causal chain, closer and closer to the experience (or relevant brain state). Perhaps one could extend the argument of this paper to show that moving from a pure qualitative condition to an experience with some content is a process in some ways similar to the process of the object moving along the causal chain. 
There is a suggestion we may want to pick up from the previous section. Perhaps teleosemantic theories can give a principled answer to the question of where to locate the objects of perception: namely, where objects of "potential adaptive significance' are found. For example, in the case of auditory perceptions, the presence of the thing emitting a sound is presumably more significant for survival than the presence of the sound; this consideration then would rule in favour of regarding things, rather than sounds, as the object of auditory experiences. If other reductive theories of content - theories that attempt to reduce intentional content to causalnomological connections - were successful, they would also be contenders for locating the objects of perception.

Reductive accounts of content face many objections, and we think there are good reasons to think that none of the theories we are familiar with is completely satisfactory. Be that as it may, our approach to this question is completely different: we propose to regard the phenomenal presence of the object as our guide in establishing what is perceived in an experience. This approach is compatible with the eventual success of reductive theories.

To introduce the idea, let us reflect for a moment on how reductive accounts of intentional content are developed and evaluated. Take for example Fodor's discussion in Psychosemantics (Fodor 1987, chapter 4). Fodor's question is somewhat different from ours: he wants to know how mental symbols represent properties, and he is interested not only in perceptual experiences, but in mental states in general. Nonetheless, as we shall see, the issue is straightforwardly relevant to our problem as well. Fodor first considers the suggestion that whatever causes the tokening of a mental symbol is represented by that symbol. This would have the result that tokenings of a certain symbol, say HORSE, represents horses and cows-in-the-dark. This is clearly unacceptable, says Fodor, and we all agree. Another, similar objection may be that if experiences (conceived either as tokening of mental symbols or in another way) represented their causes, then visual experiences could represent states of the retina. This is clearly unacceptable too.

The question is: why are these consequences unacceptable? It seems that even before we start to design a systematic theory, we already have some idea of what is, and what can possibly be - or cannot possibly be - the object of a perceptual experience or the content of a representation. We know that the object of an olfactory experience of a rose smell is not the surface of the inside of our nose, nor it is the 
gardener who planted the rose. If a theory had that consequence, it would probably count as a reductio against that theory.

Where do these initial ideas about the objects of experiences come from? We propose to further elaborate the matter by an appeal to the phenomenal character of experiences. That is, we assume, along with many other philosophers, that the nature of a perceptual - and in general, sensory - experience is given by its phenomenal character. The question about the objects of perception arises precisely because it is part of the phenomenology of perceptual experiences that they seem to present to us objects as being in a certain way. All further investigations are shaped by this initial observation.

The object of a perceptual experience is what seems to be present when having that experience. In other words, it is the object that is phenomenally present. This is clearly not an attempt at a reduction: indeed, the claim is almost tautological. However, it is still important, because we implicitly rely on it when evaluating theories of perception or intentionality. Whatever account of perception we give, one of the data we have to account for is that we see the glass in front of us, but we don't see the optic nerve, nor the hand that placed the glass here.

There are various notions, like 'signalling' or 'carrying information' that may adequately cover the relation between a perceptual experience and any member of the causal chain that leads to the experience. Perhaps experiences carry information about states of the retina, states of the optic nerve; perhaps a visual experience of the lights being on next door signals that the neighbour is at home. But the reason why we say that neither the retina, nor the neighbour is the object of the perception - that we don't see the retina or the neighbour - is that they are not phenomenally present in the experience. We don't seem to see these things when having the experience - we see (or at least seem to see) simply the lights.

The idea that the objects of perception are phenomenally present in an experience is meant to be compatible with pretty much any theory of perceptual experience. Suppose we accept a representationalist theory of perception, which holds that the nature of a perceptual experience is determined by its representational properties, which, in turn, determine the accuracy conditions for the experience. A particular visual experience is of a glass, because the experience is veridical if the glass - rather than the retina, or the glass-maker - has certain properties. Of course, we might agree with that. But how did the representationalist know where to look for 
the accuracy conditions? Why didn't she suggest that the experience is veridical if the retina is in a certain state? The simplest answer, we suggest, is that the retina doesn't seem to be the object of the experience - in other words, it's not phenomenally present in the experience. ${ }^{9}$

Appealing to the idea of phenomenal presence is not going to settle all issues about the objects of perception. First, there may not always be a consensus on what is phenomenally present in someone's experience. Each of us has to rely on their firstperson reports, and some people may be better than others in attending to the phenomenal features of their experiences. In some cases, there may be some uncertainty at first whether something is phenomenally presented in an experience or its presence is evoked as a result of some association, and then different kinds of considerations might be used to decide the question. Besides, as we noted, the guidance of phenomenal presence is compatible with many, otherwise different theories, so clearly, not all questions will be solved this way.

But even if there will be unclear cases, it seems obvious that there are clear cases as well. As we said before, most philosophers will agree that one's own olfactory bulb is normally not the object of an olfactory experience. To argue that the olfactory bulb is the object of an olfactory experience requires significant further work. So it seems that we do use the condition of phenomenal presence as the default position to exclude certain objects as candidates for being the object of a perceptual experience.

\section{$\underline{6 .}$ Phenomenal presence and different kinds of objects}

It's part of the phenomenology of perceptual experiences that objects seem to be presented to us; so the first and foremost clue when locating the objects of perceptual experiences is to see what is phenomenally present in our experiences. And our reason for insisting that perceptions can take different kinds of objects in a given modality is that we think that these different kinds of things can all have the appropriate phenomenal presence in our perceptual experiences. Without a further argument against these things being the object of an experience, we suggest we should take phenomenology at face value.

To clarify: we do think that for any particular episode, one can single out the

9 A similar notion of phenomenal presence is used for a similar purpose - ie to locate objects of representation among the many causes of representation - by Galen Strawson in Strawson (2008). 
perceived object(s) among the causes. We don't think that the very same token olfactory experience can take an odour or a flower as its object, depending on some further factors. When we argue for the possibility of different kinds of objects, we merely say that we cannot in general establish that all olfactory experiences take only one or other kind of thing as their object.

Compare two situations: you enter a room and an unexpected smell hits you or you enter a room and you smell coffee; we say that from a phenomenological point of view, the odour and the coffee are present in your experience in the same apparently unmediated way. So in the first case, the object is only the odour, in the second case, the objects include the source of odour (and possibly the odour as well). Another case: you feel a soft caress your arm - or your are searching in your bag for your key and suddenly your fingers touch it; in the first case, you are aware only of some sensation on your skin, in the second case, (also) of the object that touches the skin. Here again, we say that your skin (as you feel the sensation in your arm) and the key have the same sort of phenomenal presence, and therefore both count as objects of perception. (More on the objects of bodily and tactile experiences in sections 8 and 9; the foregoing was just one example of how something may be added to an experience as an object.)

As these examples show, one factor that often plays a role in determining the object of a particular perceptual episode is the totality of our previous experiences. Coffee becomes phenomenally salient in our experience after repeated encounters with coffee; familiarity with the shape of the key and our purpose in the search makes the key phenomenally present. In the second case, the focus of attention is an additional factor in determining the phenomenal presence: if we are in an exploratory mode, shapes might strike you differently than in the case of an unexpected stimulus.

There are two parts to the defence of the claim that the object of, say, an olfactory experience can be located at different points in the causal chain: first, we have to show that in some cases, the only object is the odour; second, we have to show that in some other cases, the source of the odour is really an object. We need both parts, because otherwise someone could hold a view, similar to Lycan's view, that olfactory experiences always have multiple objects: we perceive the source by perceiving an odour. If that was the case, then we could establish uniformly, for all cases of the olfactory modality, which elements in the causal chain are objects of the experience. But our contention is that we cannot establish this. 
The most plausible cases for smelling only odours are those of dispersed and unfamiliar smells. You are walking on a deserted country road and suddenly a peculiar, faint and slightly stale smell hits your nose. You have no conception of the origin of the smell; the faintness and staleness is characteristic of a lingering smell rather than a freshly produced smell. We think that it would be implausible to say that in this case, any object beyond the odour itself is phenomenally present in your experience.

A different kind of case is when you feel a feel a familiar smell, clearly associated with a source, perhaps even answering to some need or expectation. You arrive at a friend's house for brunch after a bad night sleep; you smell freshly brewed coffee, and you immediately look for the coffee pot. Maybe this is one of the cases that fits Lycan's idea of perceiving objects with potential adaptive significance: what matters for your survival that morning is the coffee, not its odour, and this may explain its phenomenal salience in your experience. Since the coffee is presented in your experience, it is an object of the experience.

\section{Unconscious inference or association?}

We have been arguing that on some occasions, the object of an olfactory experience is an odour, on other occasions, it is (also) the source of the odour. This supports our claim that within a sensory modality, one cannot fix the object of the experience for all cases. Our main argument for claiming that the object may vary from case to case is based on an appeal to the phenomenal presence of the object. Sometimes it's the odour, sometimes it's (also) the source of the odour that is phenomenally present in an experience.

A possible objection is that we don't in fact smell the coffee in the second case, but we merely make a quick unconscious inference to the presence of coffee, or that an immediate association of the smell and the coffee brings the idea of coffee to mind (in the latter case, we need not say that any inference took place). Coffee is not the object of the perceptual experience, according to this objection, but of a separate mental state, probably a judgement. The coffee case then would be similar to the case of 'seeing' that it's cold outside: we don't literally see the cold, we only learn that it is cold on the basis of a visual experience.

According to the view which is behind this objection, the inference or association is unconscious. This is important, because it doesn't seem that in the 
specific cases we have in mind, there is an intermediate step. The idea of coffee comes to you directly upon entering the house, and immediately prompts a reaction. (Similarly, to anticipate the discussion of tactile experiences, when your fingers close around the key in your bag, the process doesn't seem to consist of two steps: first, the identification of the sensation on your skin, and then matching it with an awareness of the external object. Instead, you just feel the key.)

We do not want to say, at this point, that when you smell the coffee, you cease to be aware of the odour, and when you feel the key, you cease to be aware of a condition of your skin. In fact, we'd like to leave this question open. What we want to say is merely that it doesn't seem that awareness of the coffee or the key is reached through an intermediate step. It seems possible to be aware of two different objects without the phenomenology of indirectness. An analogous case, involving properties rather than objects, might be the example we mentioned above about seeing pine trees. Susanna Siegel's claim that experiences (can come to) represent natural kind properties does not entail that when they do, they cease to represent simpler properties like colours or shapes. If Siegel is right, and when developing a recognitional capacity for pine trees, you start to be perceptually aware of something being a pine tree, this doesn't mean that you cease to be perceptually aware of the shapes and colours that determine that something looks like a pine tree. Furthermore, and that's the crucial point, the property of being a pine tree that according to Siegel enters the content of the perceptual experience, does not seem to be represented in the content of a mental episode as somehow being inferred from, or following upon, the original perceptual experience of shapes and colours.

Now back to the suggestion that we don't perceive, but merely unconsciously infer, or make an association with, the presence of coffee. Our reply is that this objection is based on a false contrast between perception and the involvement of unconscious inference or association. If an unconscious inference or association is involved in a perceptual process, this doesn't mean that the inference starts from a perceptual experience and leads to a separate mental state. It's very much possible that the unconscious process precedes the formation of the perceptual experience itself.

There is overwhelming evidence that our perceptual experiences are results of a substantial amount of unconscious work performed by our perceptual system. This is especially well-documented in the case of visual perception. ${ }^{10}$ Take for example the 10 There is a debate about how this 'work' is best characterised: for example, as an 
hollow-face illusion (Gregory 1973, pp. 49-96). The stimuli that reach the sensory organ are compatible with both a concave and a convex surface under different illumination conditions, and yet the resulting experience is always of a convex surface. It seems that the best way to explain this fact is to assume that our perceptual system plays an active part in the producing a perceptual experience. One idea is that because of previous experiences of faces which were all convex, the visual system 'judges' it to be much more likely that the present experience is of a convex surface, and hence infers from the ambiguous stimuli to the presence of a convex surface. Of course, if there is inference here, it must be unconscious, and some people even object to saying that the visual system can do anything like judging or inferring, and some other expression should be used. Be that as it may, the unconscious inference cannot be understood as starting from a perceptual experience and resulting in a separate mental state. Instead, the inference precedes the experience itself: there is no doubt that we have a genuine visual perception of the face as convex.

The relevant examples vary a great deal, but the upshot is the following. Just because unconscious association or interpretation, based on previous experiences, is involved in a perceptual process, this doesn't mean that there is first a perceptual experience, and then the interpretation produces a separate judgement. The unconscious interpretation may well be part of the formation of the perceptual experience itself. We need an explanation of why unconscious interpretation in the coffee case is different from unconscious interpretation in the case of the hollow face illusion; until the difference is demonstrated and shown to have explanatory advantages over our proposal, phenomenal presence remains the best guide to what the object of perception is.

We did say above that phenomenal presence may not settle all issues about the objects of perception. We do insist, however, that it is our primary guide, and if phenomenal presence singles out something as an object of a perceptual experience, we need further, and decisive reasons to dismiss the testimony of phenomenal presence. On this basis, coffee qualifies as an object, and the fact that this is the result of an unconscious interpretation does not disqualify its status as object of perceptual

unconscious inference following Bayesian principles, or merely as a process conforming to various laws. This debate is not our concern here: we simply want to rely on the fact that the content of perceptual experiences is not entirely determined by the stimuli on our perceptual organs, but requires the active contribution of the perceptual system as well. 
experience.

One question may remain, however: what is then the difference between the coffee case and the case of 'seeing' that it's cold? Why doesn't the second qualify as a genuine case of perceiving temperature? We shall answer this question in the next section.

\section{Objects of tactile experiences}

In this section and the next we shall illustrate how the object of perception can move along the causal chain in the case of experiences in the tactile modality. Philosophers have expressed different views about what should be regarded as the object of touch. On the most 'minimal' version, the object is some part of the skin: in touching something, we feel a pressure on our skin. A possible variation on this view would also include the muscles communicating the magnitude of pressure.

Perhaps some people don't regard the skin or the muscles as proper 'objects' of experience; they may argue that these cases are better described as mere sensations, that is, sensory experiences without a perceptual object. We do not need to take issue with this, because this way of looking at things still fits our general thesis: the object of experience is not fixed for a certain sensory modality. However, what matters here is that tactile objects and bodily parts are different links identified along the same causal chains that result in perceptual experiences. For the sake of simplicity, we will continue talking of 'tactile experiences' as covering both cases of bodily and tactile perception.

If the skin and what's within the skin are the only objects of a tactile experience, anything that extends further than the skin must be the object of a separate mental state. This is the view held by Fred Dretske, for example:

... even if we can tell the shape of things by touch (i.e., feel that it is square), I do not think this shows we feel the object's shape. What we feel when we tell the shape of objects in this way is pressure and (if this is really different) texture. It is differences in pressure we feel as we move our hand around the object that (together with what we know about how we are moving our hand) tell us what shape an object is. [...] If this is to count as feeling shape, then wine connoisseurs must be tasting colors (Dretske 2000, pp. 458-9). ${ }^{11}$

11 That is, the claim that extrabodily objects are not the objects of tactile experiences is Dretske's 
To be precise, Dretske is talking here about the question of which properties, rather than which things are perceived. But there is an obvious connection between these questions: perceiving a thing is perceiving it as being in some way, that is, as exemplifying some properties. Presumably, the properties that enter the content of an experience are the ones exemplified by the things we perceive. Hence if shape and texture are not something we literally perceive when having a tactile experience, then the object that has the shape and texture is not the object of the experience.

Dretske's claim about tactile experiences falls within our discussion from the previous section and so all the considerations and conclusions there apply to the present case. That is, since objects outside the skin often have an immediate phenomenal presence in tactile experiences, on our account, they qualify as objects of perception.

We agree that it would be odd to grant that wine connoisseurs taste colours, but we deny that tactile experience of extrabodily objects is analogous to 'tasting colours'. First, even for expert wine tasters, it is questionable how much the colour of the wine is phenomenally present in a gustatory experience. Take one of the more easily identifiable grape varieties, for example pinot noir. It seems conceivable that similarly to the example of the pine tree, someone can develop a reliable recognitional capacity for pinot noir through tasting, and being pinot noir becomes part of the content of their gustatory experience. Pinot noir is red, so one can readily identify the colour of the wine on the basis of the flavour. But this isn't the same as having redness phenomenally present in one's gustatory experience: the identification of the pinot noir flavour does seem to be an intermediary step on the way to the identification of colour.

Why is there an intermediary step? Because it seems that there is no phenomenally unified category of the flavour of red (or the flavour of white, for that matter). Red wines of different grape varieties or by different makers taste very different, and then we haven't even considered other red beverages, like raspberry juice or rooibos tea. This is why the identification of colour on the basis of flavour seems to us indirect: the flavour that indicates red is too diverse to make it possible for $r e d$ to be presented phenomenally in a gustatory experience.

view only in case he regards feeling texture as "really different" from feeling pressure. We'll assume here that this is his view while the reader should keep in mind the qualification 'unless texture is different from pressure'. 
To come back to the question we left unanswered at the end of the previous section: the same holds for our earlier example of 'seeing' that it's cold. The visual appearance of it's being cold is just too diverse to form a category that could be directly phenomenally present in experience. We learn that it's cold when we see snow, ice, people wearing thick coats, their having red noses and blue lips, their breath steaming in the cold air, and so on. There is no such thing as phenomenal category of 'the look of cold'.

But the case of felt shapes, textures and temperatures is different. In these cases, there is a phenomenally robust quality that is present in tactile experiences. That is why we find it overwhelmingly plausible that in these cases, the thing which has the shape or texture can be a genuine object of the perceptual experience.

As before, to show that the object of experience moves along the causal chain, we need to present instances both of feeling only the condition of the skin or bodily part, and other instances when we feel (also) the object that touches the skin. We have already mentioned a couple of relevant examples. The most plausible cases of feeling only a bodily part are cases of unexpected, fleeting and unfamiliar tactile sensations. If the sensation is unpleasant - for example a sort of sting verging on the slightly painful - then it's all the more plausible that the centre stage of one's phenomenal awareness in the experience is taken up by the skin, with no room left for the offending object that caused the sensation.

How different this is from a purposeful search among familiar objects. The earlier example was searching for a key; another one may be finding the utterly familiar location of the switch of your bedside lamp in the dark. It seems to us that as soon as one's finger hits on the switch, we do genuinely feel its presence.

\section{Further explored objects}

So far we mentioned two categories of possible objects for tactile experiences: bodily parts, and objects immediately touching the body. In addition, further explored objects may become the objects of touch. Aristotle remarks that an object that comes in contact with the skin is at once perceived. Furthermore,

if the experiment is made of making a sort of membrane and stretching it tight over the flesh, as soon as this web is touched the sensation is reported in the same manner as before, yet it is clear that the organ is not in this membrane. If 
the membrane could be grown on to the flesh, the report would travel still quicker (Aristotle, Book II, §11 422b33-423a12).

A contemporary example could be a surgeon wearing a surgical glove. Although the glove is the only thing that is strictly speaking in contact with the skin, the surgeon can plausibly be said to feel also the shape of the scalpel she is manipulating. More striking examples involve putting more distance between the skin and the perceived object, for example in the case of exploring the shape and surface of objects with a stick - that is, if one finds the following description by Merleau-Ponty plausible:

Once the stick has become a familiar instrument, the world of feelable things recedes and now begins, not at the outer skin of the hand, but at the end of the stick. ... the habit does not consist in interpreting the pressures of the stick on the hand as indications of certain positions of the stick, and these as signs of an external object, since it relieves us of the necessity of doing so. The pressures on the hand are no longer given; the stick is no longer an object perceived by the blind man, but an instrument with which he perceives. (Merleau-Ponty 1945, pp. 175-6)

An interesting example of tactile experience acquiring new objects can be the case of the users of tactile visual substitution system (TVSS, see Bach-Y-Rita1996). A camera records an image which is simplified into a black-and-white pixellated image, which in turn is converted into vibratory or electric stimuli produced by a plate against the skin of the subject. The subject feels the converted shapes through tactile experience. After sufficient training, subjects learn to locate and manipulate objects in space. Interestingly

when the man-machine interface, the electro- or vibrotactile array, is moved from one area of skin to another (e.g., from the back to the abdomen or to the forehead), there is no loss of correct spatial localization, even when the array is switched from back to front, since the trained blind subject is not perceiving the image on the skin, but is locating it correctly in space. (Bach-Y-Rita 1996, p. 500) 
On the basis of considerations put forward above, we regard it as plausible that the object whose image is conveyed through the array becomes here the object of the experience. ${ }^{12}$

Both Merleau-Ponty's description and the reports about using sensory substitution systems raise a question that we already touched upon in passing: when a more remote link in the causal chain is added as an object, do we cease to perceive the more proximate links? Going back to the case of olfaction, the question would be whether we cease to perceive an odour, once its source becomes the object of the olfactory experience. Or similarly for tactile modality - do we cease to perceive what happens to the palms of our hands once we engage in an active exploratory touch of an extrabodily object? We cannot settle the question here, but some possible answers were already mentioned. Lycan's layered-representation view of olfaction holds that we always perceive the odour as well as the source of the odour. Merlau-Ponty has a different view in the case of touch: once the stick becomes a familiar tool, it ceases to be an object of perception, and the only things felt are the explored surfaces.

\section{Conclusion}

It's part of the phenomenology of perceptual experiences that objects seem to be presented to us. The first guide to objects is their perceptual presence. Further reflection shows that we take the objects of our experiences to be among the causes of our experiences. However, we do not think that all causes of the experience are also objects of the experience. This raises the question indicated in the title of this paper. We argued that taking phenomenal presence as the guide to the objects of perception, we can see that at least in two sensory modalities, smell and touch, there is no uniform answer to this question. The objects of olfactory and tactile experiences can move along the causal chain.

\section{References:}

Aristotle, "On the Soul” Trans. by J. A. Smith, in Barnes, Jonathan (ed.), The Complete Works of Aristotle. Princeton University Press. 1995. 641-692.

12 Tactile visual substitution system (TVSS) is but one of the many sensory substitution systems that have been developed and tested, and other cases seem to confirm that the subjects using the systems come to perceive new objects previously not experienced in the modality (see Bach-y-Rita 1996). 
Bach-Y-Rita, Paul (1996) "Sensory substitution and qualia" in Alva Noë and Evan Thompson (eds.) Vision and Mind. Cambridge, Mass.: MIT Press 2002. pp. 497514

Bayne, Tim (2009), "Perceptual Experience and the Reach of Phenomenal Content" The Philosophical Quarterly, Vol. 59, pp. 385-404.

Berkeley, George (1734) Three Dialogues in: Desmond M. Clark (ed.) Philosophical Writings. Cambridge University Press 2009. pp. 151-242.

Dretske, Fred (2000), "Reply to Lopes", Philosophy and Phenomenological Research, vol. 60 , pp. 455-459

Gregory, Richard (1973) Illusion in Nature and Art (London: Duckworth)

Heidegger, Martin (1950) "The Origin of the Work of Art" in Richard Kearney, David M. Rasmussen (eds.) Continental Aesthetics, Blackwell 2001: pp. 182-211

Fodor, Jerry A. (1987): Psychosemantics. Cambridge, Mass.: MIT Press

Lycan, William G. (1996). "Layered Perceptual Representation". Philosophical Issues 7: pp. $81-100$

Merleau-Ponty, Maurice (1945) Phenomenology of perception. trans. by Colin Smith, (London: Routledge \& Kegan Paul, 1962) translation revised by Forrest Williams, 1981; reprinted, 2002.

Nudds, Matthew (2004) 'The Significance of the Senses', Proceedings of Aristotelian Society, New Series, Vol. 104, pp. 31-51.

O'Callaghan, Casey (2007) Sounds. A Philosophical Theory, Oxford UP.

Peacocke, Christopher (1983) Sense and Content. Experience, Thought and their Relations, Oxford UP.

Sanford, David H. (1976) “The Primary Objects of Perception” Mind vol.85. pp.189208

Siegel, Susanna (2006) "Which Properties are Represented in Perception?” in Tamar Gendler Szabo and John Hawthorne (eds.) Perceptual Experience Oxford University Press. pp. 481-503

Siegel, Susanna (2013) "The Contents of Perception", The Stanford Encyclopedia of Philosophy (Spring 2013 Edition), Edward N. Zalta (ed.), forthcoming URL = $<$ http://plato.stanford.edu/archives/spr2013/entries/perception-contents/>.

Strawson, Galen (2008) "Real Intentionality 3" in his Real Materialism and Other Essays, Oxford University Press. pp. 281-305

Travis, Charles (2004) "The silence of the senses" Mind 113 (449): pp. 57-94

Tye, Michael (1995) Ten Problems of Consciousness, Cambridge, Mass.: MIT Press 